\title{
Longitudinal study of associated factors with adolescent health: Method and sample profile
}

\section{Estudo longitudinal de fatores associados à saúde do adolescente: Método e perfil amostral}

\author{
Gustavo Aires de Arruda ${ }^{1}$ \\ (D) https://orcid.org/0000-0002-9157-6114 \\ Diogo Henrique Constantino Coledam 2 \\ (i) https://orcid.org/0000-0001-6211-7069 \\ Francys Paula Cantieri $\mathbf{1}$ \\ (D) https://orcid.org/0000-0002-1132-4540 \\ Mauro Virgílio Gomes de Barros 1 \\ (1) https://orcid.org/0000-0003-3165-0965 \\ Diego Augusto Santos Silva ${ }^{3}$ \\ (i) https://orcid.org/0000-0002-0489-7906 \\ Amanda Oliveira Bernardino Cavalcanti de Albuquerque ${ }^{1}$ \\ (1D) https://orcid.org/0000-0002-1011-8964 \\ Clara Maria Silvestre Monteiro de Freitas 1 \\ (D) https://orcid.org/0000-0002-4066-7702 \\ Arli Ramos de Oliveira 4 \\ (D) https://orcid.org/0000-0003-4503-9083
}

Abstract - The aim of this work was to describe the methodological procedures of a longitudinal study on adolescent health, as well as to characterize the sample profile. This research enrolled a sample of 302 adolescents from Londrina - Paraná. Two data collections were carried out with an interval of three years. Anthropometric indicators, blood pressure, heart rate, back pain, academic achievement, physical activity, sedentary behavior, eating habits, alcohol consumption, smoking, socioeconomic status, and motor tests were collected. There was a frequency of high blood pressure of $10.4 \%$; body mass index in conditions associated with health risk of $22.4 \%$; and spinal pain with moderate intensity of $22.1 \%$. Sport and/or physical exercise practice (moderate-to-vigorous; $\geq 150$ minutes/week) was $33.1 \%$. High consumption of unhealthy foods and beverages ranged from $21.2 \%$ (coffee or tea) to $58.0 \%$ (fried foods). A high proportion $(87.1 \%)$ reported never having smoked. The grades frequency $\geq$ seven varied between 21.4\% (Biology) and 71.1\% (Physical Education). Only 33.2\% presented high academic achievement. The highest compliance with criteria was in the curl-up (76.4\%) and the lowest in the $90^{\circ}$ push-up (37.2\%). This work will make it possible to verify the tracking of different behavioral and biological indicators related to health, as well as academic achievement. It will also allow the identification of the association between health outcomes and exposure factors prospectively, considering the influence of potential confounding variables. This information could contribute to the planning of public health interventions and policies.

Key words: Academic performance; Eating behavior; Hypertension; Low back pain; Obesity.

Resumo - O objetivo deste trabalho foi descrever os procedimentos metodológicos de um estudo longitudinal sobre a saúde de adolescentes, bem como caracterizar o perfil da amostra. Participaram desta pesquisa 302 adolescentes (13,9 1,2 anos) de Londrina - Paraná. Duas coletas de dados foram realizadas com intervalo de três anos. Foram coletados indicadores antropométricos, pressão arterial, frequência cardiaca, dor na coluna, desempenho escolar, atividade física, comportamento sedentário, hábitos alimentares, consumo de bebidas alcoólicas, tabagismo, condição socioeconômica e testes motores. Verificou-se frequência de pressão arterial elevada de 10,4\%; indice de massa corporal em condições associadas com risco à saúde de 22,4\%; e dor na coluna com intensidade moderada de 22,1\%. A prática de esporte elou exercício físico (moderada à vigorosa $: \geq 150$ minutos/semana) foi de $33,1 \%$. O consumo elevado dos alimentos e bebidas não saudáveis variou de 21,2\% (café ou chá) a 58,0\% (frituras). Elevada proporção $(87,1 \%)$ relatou nunca ter fumado. As prevalências de notas $\geq$ sete, variaram entre 21,4\% (Biologia) e 71,1\% (Educação Física). Apenas 33,2\% tiveram desempen ho escolar elevado. $O$ maior atendimento de critérios foi no abdominal $(76,4 \%)$ e o menor flexão de cotovelos $(37,2 \%)$. Este trabalho possibilitará verificar a estabilidade de diferentes indicadores comportamentais e biológicos relacionados à saúde, bem como do desempenho escolar. Permitirá a identificação da associação entre desfechos em saúde e fatores de exposição de forma prospectiva, considerando a influência de potencia is variáveis de confusão. Tais informaçôes podem contribuir para o planejamento de intervençôes e políticas públicas na área da saúde.

Palavras-chave: Comportamento alimentar; Desempenho acadêmico; Hipertensão; Dor lombar; Obesidade.
1 University of Pernambuco. Recife, PE. Brazil.

2 Federal Institute of Education, Science and Technology of São Paulo. Boituva, SP. Brazil.

3 Federal University of Santa Catarina. Florianópolis, SC. Brazil.

4 Londrina State University. Londrina, PR. Brazil.

Received: February 11, 2020 Accepted: June 23, 2020

How to cite this article Arruda GA, Coledam DHC, Cantieri FP, Barros MVG, Silva DAS, Albuquerque AOBC, Freitas CMSM, Oliveira AR. Longitudinal study of associated factors with adolescent health: Method and sample profile. Rev Bras Cineantropom Desempenho Hum 2020, 22:e71432. DOI: http://dx.doi.org/10.1590/19800037.2020v22e71432

Copyright: This work is licensed under a Creative Commons Attribution 4.0 International License. 


\section{INTRODUCTION}

Health can be defined as a dynamic state of wellbeing, characterized by a physical, mental and social potential, which satisfies the demands of a life commensurate with age, culture, and personal responsibility. If the potential is insufficient to satisfy these demands the state is disease ${ }^{1}$. Blood pressure, obesity, and physical fitness have been highlighted due to their relationship with early morbidity and mortality ${ }^{2-4}$. Spinal pain has received great attention, as it is one of the main factors responsible for years lived with disability ${ }^{4}$, difficulty to engage in healthy behaviors ${ }^{5}$, low academic achievement ${ }^{6}$ and generates high health costs ${ }^{7}$. Insufficient physical activity ${ }^{8,9}$, high sedentary behavior ${ }^{10}$, and inappropriate eating habits seem to be in the causal chain of these outcomes, ${ }^{8,11}$ as well others including mental health ${ }^{12}$.

The evidence about associations between health outcomes and the adoption of different behaviors is complex and does not always show consistent results. Part of the divergences seems to occur due to cross-sectional designs, which make it difficult to establish a causal relationship, in addition to presenting the possibility of reverse causality. Another relevant aspect is the verification of potential confounding variables, which are often not investigated ${ }^{13,14}$. Longitudinal studies contribute to understanding the relation between exposures and health-related outcomes. However, the main barriers to their realization are logistical difficulties and higher cost.

Different strategies have been adopted in longitudinal studies to deal with these barriers. At times, instruments with greater difficulty were applied to random samples. Subsequently, according to specific objectives, only these individuals were invited to perform some follow-ups ${ }^{12,15}$. Similar strategies can be observed in studies carried out in Brazil, as well as which, some measures involving higher costs were carried out only at a few moments?

Longitudinal studies that investigate the relationship between behaviors and different health-related outcomes are still scarce in Brazil. This information is of great importance, as it could contribute to understanding of the relationship between different behaviors and the onset of health outcomes, thus providing elements for directing intervention strategies and contributing to the planning of public policies. Therefore, the aim of the present study was to present the methodological procedures of a longitudinal study on adolescent health, as well as to describe the sample profile.

\section{METHODS}

\section{Design and procedures}

Longitudinal study involving adolescents from Londrina, Paraná, Brazil. There was between the baseline and follow-up a mean interval of 3 years $( \pm 2$ months). Reliability of the information was verified in the baseline (Figure 1). A pilot study ( $\mathrm{n}=58$ ) was carried out with adolescents who did not compose the sample, aiming at training researchers, standardizing procedures, and 
identifying the technical error of measurement (TEM) of anthropometric variables. Study protocols were approved by the Ethics in Research Committee from the university where the study took place (Protocol no. 234/10).

\section{Population and sample}

Londrina City had 48,688 students enrolled in state schools (publicly administered institutions) at the beginning of the study, from $5^{\text {th }}$ grade of elementary school to the $3^{\text {rd }}$ grade of high school. A total of 30,777 students were attending the $5^{\text {th }}$ to $8^{\text {th }}$ grades. Regarding the $1^{\text {st }}, 2^{\text {nd }}$ and $3^{\text {rd }}$ high school years, 17,911 students were enrolled in state schools (data from the City Department of Education of Londrina, referring to the year 2009). In the present study, schools with 400 to 800 enrolled students were considered medium-sized schools, and with more than 800 enrolled students were considered large schools. The number of enrolments was proportionally distributed among small, medium, and large schools in the city. Two state schools were randomly selected for the composition of the sample in the present study: a medium-sized school (central region) and a large one (northern region). Classrooms were randomly selected in each school (conglomerate). The sample involved approximately $50 \%$ of the participants of each school.

To determine sample size at baseline the calculation ${ }^{16}$ was performed based on a prevalence of $7.7 \%$ of high blood pressure $(\mathrm{HBP})^{17}$ and a tolerable error of 3\%. The sample size calculated was 301 participants for a simple random sample. A correction for design effect of 2.0 was performed, thus requiring at least 603 participants. To offset the effect of any losses, a total of $15 \%$ was added. After these, the number of participants established was 693. The baseline involved 708 regularly enrolled schoolchildren (boys and girls), aged between 12 and 18 years.

At follow-up, 322 individuals were considered eligible, as they were still of school age (Figure 1). In a future study, the main objective will be to verify the association between HBP at baseline and HBP at follow-up. Crude and adjusted odds ratios with $95 \%$ confidence intervals $(95 \% \mathrm{CI})$ will be obtained with logistic regression models.

\section{Data collection procedures}

Procedures were performed during Physical Education classes in the following order: questionnaires (physical activity, eating habits and alcohol consumption, back pain, smoking, and socioeconomic status), blood pressure, heart rate, and anthropometric measurements (body mass, height, circumferences, and skinfolds) performed in the classroom. Motor performance was subsequently verified in a covered multi-sports court ${ }^{3,18}$. In the follow-up, questionnaires, blood pressure, heart rate, body mass and height were verified following the same procedures.

Physical activity and sedentary behavior data were obtained through the Baecke Questionnaire of Habitual Physical Activity-BQHPA. The $\mathrm{BQHPA}$ is structured in 3 sections; the first considers physical activities at 


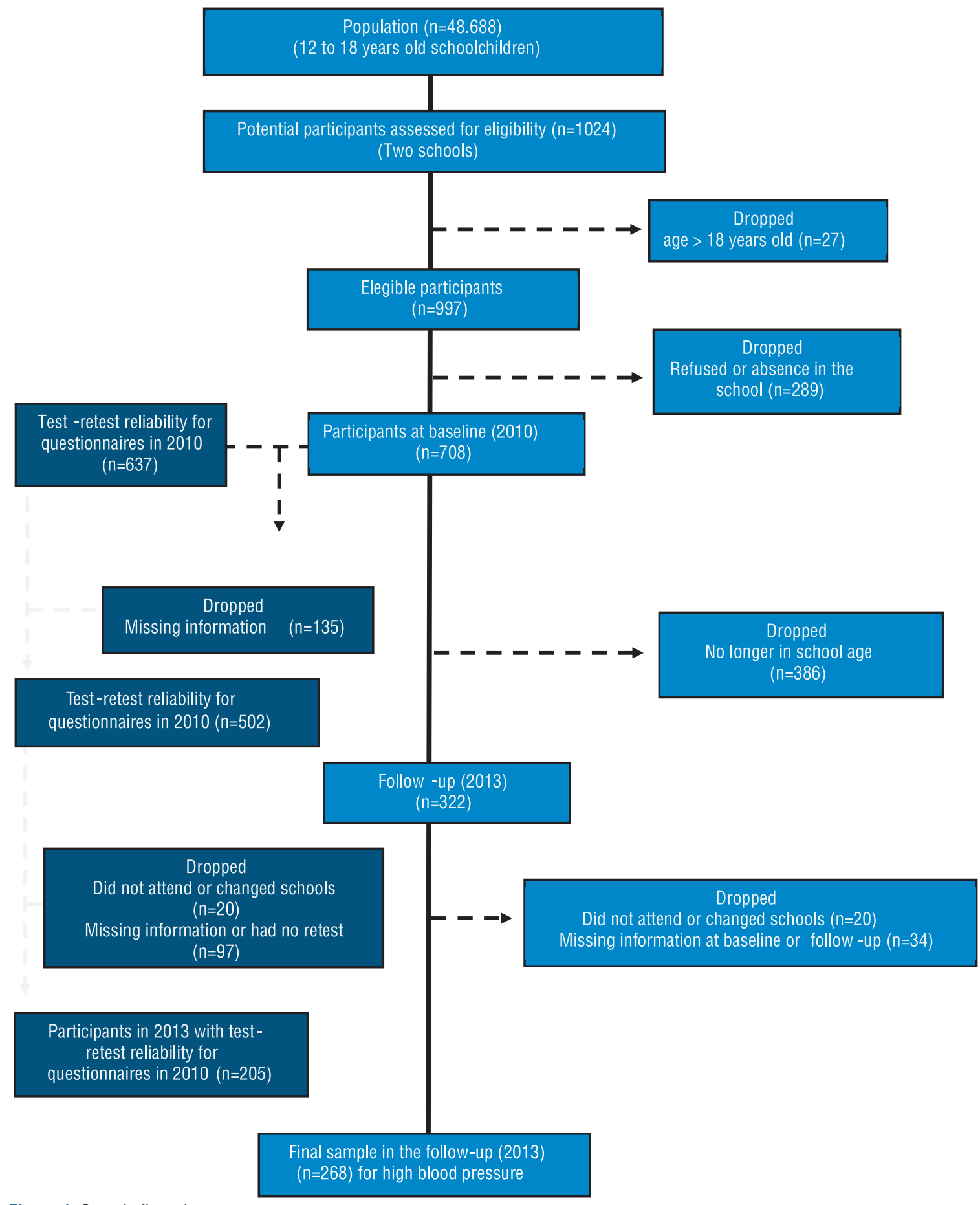

Figure 1. Sample flow chart.

school, the second, sports during leisure time, and the third, physical activity during leisure time. The scores were calculated according to standardized procedures with higher scores indicating greater physical activity. From dimension two, questions nine through 9.6 were used to obtain information about sport and/or physical exercise (SPE) ${ }^{19}$. Participants were classified as sufficiently active (moderate-to-vigorous; $\geq 150 \mathrm{~min} /$ week), insufficiently active (moderate-to-vigorous; $<150 \mathrm{~min} /$ week), and non-practitioners. 
Eating habits was verified using a recall tool, specifically built for the study. Participants were instructed to consider the consumption of a normal week and report on which days and the quantity, considering homemade measures, they usually consume each food and drink. Reliability $(10 \pm 3$ days) was verified ( $\mathrm{n}=186)$ and the intraclass correlation coefficients range between 0.88 (95\% CI=0.84-0.91) for coffee or tea to 0.65 (95\% CI $=0.52$ 0.74 ) for sweets. High consumption was classified as $\geq 8 /$ week (fried foods, coffee or tea, cola drinks, other types of soft drinks except "cola types" and sweets), $\geq 4$ /week (chips) or $\geq 1 /$ week (alcoholic beverages).

Spinal pain (cervical, thoracic, and lumbar) was verified using an instrument proposed for young people ${ }^{20}$. In the analysis of the presence of pain in the spine, a value $\geq 3 \mathrm{~cm}$ on scale was used as an indicator of the presence of pain equal to or greater than moderate ${ }^{21}$.

Tobacco use was verified with the question: Are you a smoker? With five answer options: (a) No, I have never smoked; (b) No, but I have smoked before; (c) Yes, I smoke occasionally; (d) Yes, I smoke at least once a week; and (e) Yes, I smoke daily. Participants who reported smoking at least once a week or daily's were considered smokers. Reliability (10 \pm 3 days) was verified $(\mathrm{n}=233)$ and the agreement was $97.4 \%$ with Kappa of 0.92 (95\%CI=0.86-0.98).

The parent's education was verified by a questionnaire and was dichotomized between: <Complete high school and $\geq$ Complete high school. The socioeconomic classification was obtained using the same questionnaire ${ }^{22}$. Reliability (10 \pm 3 days) for the socioeconomic classification was verified $(\mathrm{n}=194)$ and the agreement was $77.3 \%$ with Kappa of 0.69 (95\%CI=0.61-0.77).

The final results of each discipline at the baseline and follow-up moments were used to analyze academic achievement. The final results were composed by the grades of the $1^{\text {st }}, 2^{\text {nd }}, 3^{\text {rd }}$, and $4^{\text {th }}$ quadmesters for teaching of the subjects organized annually. In block teaching, the final result was composed by the scores of the two bimesters in which each subject was taken, and it were considered the scores of all subjects taken in each year of the data collection. Elementary school students (Phase II) studied the following subjects in their curriculum: Arts, Physical Education, Geography, History, Portuguese Language, Mathematics, Modern Foreign Language, and Sciences. High school students have the first seven subjects, plus: Biology, Chemistry, Physics, Sociology, and Philosophy. The State Department of Education/Superintendent of Education ${ }^{23}$ of the Paraná State, in Instruction No. 011/2014, standardizes the procedures for issuing the final report of the State Education System. A minimum requirement of 6.0 or higher is required for approval, in addition to a minimum frequency of $75 \%$ of the total workload of each subject taken in the collective organization and $100 \%$ in the individual organization. Participants were dichotomized among academic achievement " $\geq$ high" and "<high". Since the instructions indicate only the minimum criteria for approval and there are no cut-off points that designate "high" performance, in the present study participants who obtained grades equal to or greater than 7.0 in at least $70 \%$ of the subjects, and who in the other subjects obtained scores 
equal to or higher than 6.0 were considered to have performance " $\geq$ high".

Participants sat at rest for five minutes before measuring blood pressure and heart rate. An appropriate cuff for each participant was selected according to the circumference of the arm. Standardized procedures were adopted to measure blood pressure. The blood pressure of each participant was checked twice, with an interval of two minutes between measurements, and the average of the values was used for the analyses. Participants were classified as having HBP when their blood pressure value was above the 95th percentile according to their age, sex, and height ${ }^{24}$. Blood pressure and heart rate were measured by an oscillometric monitor Omron HEM 742 (Omron HealthCare, Kyoto, Japan), previously calibrated in authorized technical assistance and validated for adolescents ${ }^{25}$.

Body mass was measured with a Plenna ${ }^{\circledast}$ scale, model Acqua (Plenna Especialidades Ltda; São Paulo, Brazil) with a $0.1 \mathrm{~kg}$ unit of measurement and height with a portable stadiometer, with a $0.1 \mathrm{~cm}$ unit of measurement. The measurements were performed according to standardized procedures ${ }^{26}$. TEMs of less than $0.5 \%$ were obtained. The body mass index (BMI) was calculated by dividing body mass $(\mathrm{kg})$ by the square of height $(\mathrm{m})$. Circumferences and skinfolds were verified in part of the baseline cohort in order to verify the relationship between BMI and adiposity indicators. The adolescents who performed the measurements were chosen randomly from the classes. Waist and abdomen circumferences were measured using a Sanny ${ }^{\oplus}$ measuring tape, model SN-4010 (American Medical do Brasil Ltda; São Paulo, Brazil), with a $0.1 \mathrm{~cm}$ measurement unit, according to standardized procedures ${ }^{27}$. Subscapular, tricipital, and medial calf skinfolds were measured on the right side of the body, using a Lange ${ }^{\varpi}$ skinfold caliper, with a $1.0 \mathrm{~mm}$ measurement unit (Beta Technology Incorporated; Cambridge, USA) according to standardized procedures ${ }^{28}$. Skinfold measurements were performed by one of the researchers (GAA) with a TEM of less than 5\%. Body fat percentage was estimated by Slaughter et al. equations ${ }^{29}$. Fitnessgram criterion-referenced standards ${ }^{3}$ were used to classify participants regarding adiposity indicators.

Motor performance were verified in part of the baseline cohort. The adolescents who took the tests were randomly chosen from each class. The sit and reach from Physical Best ${ }^{18}$ and Back-saver sit and reach from Fitnessgram ${ }^{3}$ were applied. The first test to be performed was chosen randomly. For this, the evaluator drew a card before each participant performed the tests. Thus, $50 \%$ of the participants performed the Physical Best ${ }^{18}$ test first and $50 \%$ the Fitnessgram $^{3}$ test. When applying the Fitnessgram test, the same drawing procedure was carried out, in order to choose whether the participant would start the test with the right or left limb. In addition, it were applied the Shoulder Stretch, Trunk lift, Curl-up test, $90^{\circ}$ push-up, and PACER tests ${ }^{3}$. The $\mathrm{VO}_{2 \max }$ was estimated using the equation recommended by the Fitnessgram ${ }^{30}$.

\section{Statistical analysis}

The data were entered in duplicate and the EpiData 3.1 program (EpiData 
Association, Odense, Denmark) "validate duplicate files" was used to verify the consistency of the information. Any typing errors were corrected. The Kolmogorov-Smirnov test was used to verify the normality of quantitative variables. The significance adopted was $\mathrm{p}<0.05$. Measures of central tendency (mean, median, and mode) and dispersion (standard deviation and interquartile range) were used to describe the quantitative variables. For qualitative variables, absolute and relative frequency (\%) were calculated, as well as the $95 \%$ confidence interval. The analyses were performed using the IBM SPSS Statistics for Windows software, version 20 (IBM Corp., Armonk, N.Y., USA).

\section{RESULTS}

The mean age of the participants at baseline was $13.9( \pm 1.2)$ years and $53.6 \%$ were boys. The predominant economic condition was class " $\mathrm{B}$ " and a large proportion of parents had at least complete elementary school (Table 1).

Table 1. Sociodemographic characteristics of adolescents at baseline.

\begin{tabular}{|c|c|}
\hline & Mean (SD) \\
\hline Age - years $(n=302)$ & $13.9(1.2)$ \\
\hline $\operatorname{Sex}(n=302)$ & $\%(95 \% \mathrm{Cl})$ \\
\hline Girls & $46.2(40.4-51.6)$ \\
\hline Boys & $53.6(48.0-59.3)$ \\
\hline Economic class $(\mathrm{n}=274)$ & $\%(95 \% \mathrm{Cl})$ \\
\hline A (high economic power) & $11.3(7.6-15.1)$ \\
\hline B & $64.2(58.6-69.9)$ \\
\hline C & $24.1(19.0-29.2)$ \\
\hline $\mathrm{D} / \mathrm{E}$ & $0.4(0.0-1.1)$ \\
\hline Father's education $(n=279)$ & $\%(95 \% \mathrm{Cl})$ \\
\hline Illiterate / up to $3^{\text {rd }}$ year elementary school & $3.2(1.2-5.3)$ \\
\hline Up to $4^{\text {th }}$ year elementary school & $11.8(8.0-15.6)$ \\
\hline Complete elementary school & $27.6(22.4-32.8)$ \\
\hline Complete high school & $36.6(30.9-42.2)$ \\
\hline University education & $20.8(16.0-25.6)$ \\
\hline Mother's education ( $n=291$ ) & $\%(95 \% \mathrm{Cl})$ \\
\hline Illiterate / up to $3^{\text {rd }}$ year elementary school & $2.7(0.9-4.6)$ \\
\hline Up to $4^{\text {th }}$ year elementary school & $10.3(6.8-13.8)$ \\
\hline Complete elementary school & $34.7(29.2-40.2)$ \\
\hline Complete high school & $30.9(25.6-36.2)$ \\
\hline University education & $21.3(16.6-26.0)$ \\
\hline
\end{tabular}

Note. SD: Standard deviation; 95\% Cl: 95\% Confidence Interval

When analyzing biological indicators, $22.4 \%$ of the participants were classified in the "needs improvement" zone for BMI. The frequency of HBP was $10.4 \%$. In addition, a high frequency of pain in the spine with moderate intensity was observed, with $22.1 \%$ presenting pain in at least one region (Table 2). For motor performance the test with the highest frequency of achievement was the Curl-up and the least frequency was the $90^{\circ}$ push-up (Table 3). 
Table 2. Baseline health-related biological indicators in adolescents.

\begin{tabular}{|c|c|}
\hline & Mean (SD) \\
\hline Body mass - Kg $(n=292)$ & $54.3(12.7)$ \\
\hline Height - cm ( $n=290)$ & $162.1(8.5)$ \\
\hline Body mass index $-\mathrm{Kg} / \mathrm{m}^{2}(\mathrm{n}=290)$ & $20.5(4.0)$ \\
\hline Waist circumference - $\mathrm{cm}(\mathrm{n}=108)$ & $67.8(8.2)$ \\
\hline Abdomen circumference - $\mathrm{cm}(\mathrm{n}=108)$ & $74.1(8.8)$ \\
\hline Triceps skinfold - mm ( $n=74)$ & $12.52(5.47)$ \\
\hline Subscapular skinfold - $\mathrm{mm}(\mathrm{n}=68)$ & $9.6(4.7)$ \\
\hline Calf skinfold - $m m(n=72)$ & $14.1(6.2)$ \\
\hline Systolic blood pressure $-\mathrm{mmHg}(\mathrm{n}=270)$ & $111.5(12.2)$ \\
\hline Diastolic blood pressure $-\mathrm{mmHg}(\mathrm{n}=270)$ & $62.6(7.8)$ \\
\hline Heart rate - bpm $(n=270)$ & $83.7(12.9)$ \\
\hline Body mass index $(n=290)$ & $\%(95 \% \mathrm{Cl})$ \\
\hline Very lean & $9.0(5.7-12.3)$ \\
\hline Healthy fitness zone & $68.6(63.3-74.0)$ \\
\hline Needs improvement & $14.1(10.1-18.1)$ \\
\hline Needs improvement - health risk & $8.3(5.1-11.4)$ \\
\hline High blood pressure $(n=268)$ & $10.4(6.8-14.1)$ \\
\hline High systolic blood pressure $(n=268)$ & $8.6(5.2-11.9)$ \\
\hline High diastolic blood pressure $(n=268)$ & $3.0(0.9-5.0)$ \\
\hline Spine pain $-\geq$ Moderate $(n=285)$ & $\%(95 \% \mathrm{Cl})$ \\
\hline 1 region & $22.1(17.3-26.9)$ \\
\hline 2 regions & $6.3(3.5-9.1)$ \\
\hline 3 regions & $2.1(0.4-3.8)$ \\
\hline Cervical spine pain $-\geq$ Moderate $(n=291)$ & $12.0(8.3-15.8)$ \\
\hline Thoracic spine pain $-\geq$ Moderate $(n=296)$ & $13.2(9.3-17.0)$ \\
\hline Lumbar spine pain $-\geq$ Moderate $(n=294)$ & $16.0(11.8-20.2)$ \\
\hline
\end{tabular}

Note. SD: Standard deviation; 95\%Cl: 95\% Confidence Interval.

Table 3. Achievement of baseline health-related physical fitness and criterion-referenced standards in adolescents.

\begin{tabular}{|c|c|}
\hline Motor performance & Mean (SD) \\
\hline Sit and reach $-\mathrm{cm}(\mathrm{n}=115)$ & $25.1(8.7)$ \\
\hline Back-saver Sit and reach - right limb - cm ( $n=114)$ & $25.8(7.9)$ \\
\hline Back-saver Sit and reach - left limb - cm ( $n=114)$ & $25.3(7.8)$ \\
\hline Trunk lift - cm $(n=102)$ & $24.2(5.2)$ \\
\hline Curl-up - repetitions ( $n=123)$ & $41.1(25.2)$ \\
\hline $90^{\circ}$ push-up - repetitions $(n=86)$ & $9.3(8.1)$ \\
\hline PACER - Laps $(n=208)$ & $31.2(16.8)$ \\
\hline Cardiorespiratory fitness $-\mathrm{VO}_{2 \operatorname{máx}}-\mathrm{ml} / \mathrm{kg} / \mathrm{min}(\mathrm{n}=207)$ & $41.1(5.7)$ \\
\hline Motor performance - Needs improvement & $\%(95 \% \mathrm{Cl})$ \\
\hline Sit and reach $(n=115)$ & $48.7(39.6-57.8)$ \\
\hline Back-saver sit and reach $(n=114)$ & $40.4(31.3-49.4)$ \\
\hline Shoulder Stretch $(n=149)$ & $29.5(22.2-36.9)$ \\
\hline Trunk lift $(n=102)$ & $42.2(32.6-51.7)$ \\
\hline Curl-up $(n=123)$ & $23.6(16.1-31.1)$ \\
\hline $90^{\circ}$ push-up $(\mathrm{n}=86)$ & $62.8(52.6-73.0)$ \\
\hline Cardiorespiratory fitness $(n=207)$ & $\%(95 \% \mathrm{Cl})$ \\
\hline Healthy fitness zone & $42.0(35.3-48.8)$ \\
\hline Needs improvement & $21.7(16.1-27.4)$ \\
\hline Needs improvement - health risk & $36.2(29.7-42.8)$ \\
\hline
\end{tabular}

Note. SD: Standard deviation; 95\%Cl: 95\% Confidence Interval. 
Table 4. Achievement of baseline health-related physical fitness and criterion-referenced standards in adolescents.

\begin{tabular}{|c|c|c|c|}
\hline Habitual physical activity & \multicolumn{3}{|c|}{ Mean (SD) } \\
\hline Baecke index $(n=267)$ & \multicolumn{3}{|c|}{$7.8(1.3)$} \\
\hline School index $(n=301)$ & \multicolumn{3}{|c|}{$2.7(0.5)$} \\
\hline Sport index (n=292) & \multicolumn{3}{|c|}{$2.7(0.7)$} \\
\hline Leisure-time index $(\mathrm{n}=285)$ & \multicolumn{3}{|c|}{$2.5(0.7)$} \\
\hline SPE - moderate-to-vigorous ( $n=302)$ & \multicolumn{3}{|c|}{$\%(95 \% \mathrm{Cl})$} \\
\hline No & \multicolumn{3}{|c|}{$48.3(42.7-54.0)$} \\
\hline$<150 \mathrm{~min} /$ week & \multicolumn{3}{|c|}{$18.5(14.2-22.9)$} \\
\hline$\geq 150 \mathrm{~min} /$ week & \multicolumn{3}{|c|}{$33.1(27.8-38.4)$} \\
\hline Weekly consumption of food and drinks & Mean (SD) & Median (IQR) & Mode \\
\hline Fried foods $(n=300)$ & $9.9(6.2)$ & $9.0(6.0-14.0)$ & 7.0 \\
\hline Chips-type snacks ( $n=301)$ & $3.0(3.8)$ & $2.0(1.0-4.0)$ & 0.0 \\
\hline Sweets $(n=302)$ & $10.3(10.4)$ & $7.0(3.0-14.0)$ & 2.0 \\
\hline "Cola-type" soft drinks ( $n=298)$ & $11.6(13.4)$ & $8.0(3.0-15.0)$ & 3.0 \\
\hline Soft drinks - all except "cola type" $(n=298)$ & $7.8(10.3)$ & $4.5(2.0-10.0)$ & 0.0 \\
\hline Coffee or tea $(n=302)$ & $5.3(7.6)$ & $2.0(2.0-7.0)$ & 0.0 \\
\hline Alcoholic beverages $(n=299)$ & $1.4(4.4)$ & $0.0(0.0-0.0)$ & 0.0 \\
\hline High consumption of food and drinks in portions & \multicolumn{3}{|c|}{$\%(95 \% \mathrm{Cl})$} \\
\hline Fried food - $\geq 8 /$ week $(n=300)$ & \multicolumn{3}{|c|}{$58.0(52.4-63.6)$} \\
\hline Chip type snacks - $\geq 4$ /week ( $n=301$ ) & \multicolumn{3}{|c|}{$28.2(23.2-33.3)$} \\
\hline Sweets - $\geq 8$ /week $(n=302)$ & \multicolumn{3}{|c|}{$46.7(41.1-52.3)$} \\
\hline "Cola type" soft drinks - $\geq 8 /$ week $(n=298)$ & \multicolumn{3}{|c|}{$50.3(44.7-56.0)$} \\
\hline $\begin{array}{l}\text { Soft drinks - all except "cola type" - } \geq 8 / \text { week } \\
(n=298)\end{array}$ & \multicolumn{3}{|c|}{$33.6(28.2-38.9)$} \\
\hline Coffee or tea $-\geq 8 /$ week $(n=302)$ & \multicolumn{3}{|c|}{$21.2(16.6-25.8)$} \\
\hline Alcoholic beverages - $\geq 1$ week $(n=299)$ & \multicolumn{3}{|c|}{$22.7(18.0-27.5)$} \\
\hline Smoking $(n=302)$ & \multicolumn{3}{|c|}{$\%(95 \% \mathrm{Cl})$} \\
\hline No, I never smoked & \multicolumn{3}{|c|}{$87.1(83.3-90.9)$} \\
\hline No, but l've smoked before & \multicolumn{3}{|c|}{$10.6(7.1-14.1)$} \\
\hline Yes, I smoke occasionally & \multicolumn{3}{|c|}{$1.0(0.0-2.1)$} \\
\hline Yes, I smoke at least once a week & \multicolumn{3}{|c|}{$1.3(0.0-2.6)$} \\
\hline Yes, I smoke daily & \multicolumn{3}{|c|}{$0.0(0.0-0.0)$} \\
\hline
\end{tabular}

Note. SD: Standard deviation; 95\% Cl: 95\% Confidence Interval. IQR: Interquartile range; SPE: Sport and/or physical exercise.

When analyzing the SPE with moderate-to-vigorous intensity, for a period $\geq 150 \mathrm{~min} /$ week, $33.1 \%$ met the criterion. The high consumption of unhealthy foods and beverages ranged from $21.2 \%$ to $58.0 \%$. A high proportion of adolescents reported never having smoked and there were no reports of smoking daily (Table 4).

The final results for Arts ( $\mathrm{n}=253)$, Sciences ( $\mathrm{n}=211)$, Physical Education ( $\mathrm{n}=253)$, Geography $(\mathrm{n}=253)$, History $(\mathrm{n}=253)$, Foreign Language $(\mathrm{n}=253)$, Mathematics ( $n=253)$, Portuguese $(n=253)$, Biology $(n=42)$, Philosophy $(\mathrm{n}=43)$, Physics $(\mathrm{n}=41)$, Chemistry $(\mathrm{n}=41)$, and Sociology $(\mathrm{n}=41)$ were: 7.0 ( \pm 1.1$), 6.7( \pm 1.0), 7.4( \pm 0.9), 7.1( \pm 1,0), 7.3( \pm 1.0), 7.0( \pm 1.1), 6.8( \pm 1.0), 6.9$ $( \pm 0.9), 6.4( \pm 0.9), 7.7( \pm 1.3), 7.0( \pm 1.7), 6.9( \pm 1.2)$, and $6.6( \pm 1.0)$, respectively. The frequency $(95 \% \mathrm{CI})$ of scores equal to or greater than seven were: $49.8 \%$ (43.6-56.0), 35.1\% (28.6-41.5), 71.1\% (65.6-76.7), 53.8\% (47.6-59.9), 
60.5\% (54.4-66.5), 49.8\% (43.6-56.0), 39.5\% (33.5-45.6), 45.5\% (39.3-51.6), $21.4 \%$ (9.0-33.8), 65.1\% (50.9-79.4), 48.8\% (33.5-64.1), 51.2\% (35.9-66.5), and $36.6 \%$ (21.8-51.3), respectively. The frequency of high achievement $(\mathrm{n}=253)$ was $33.2 \%(27.4-39.0)$.

\section{DISCUSSION}

The present study described methods and sample profile of a longitudinal study conducted with adolescents. The main results were high frequency of HBP, moderate intensity spinal pain and needs improvement for all components of physical fitness. A high proportion of adolescents did not meet the criteria used for SPE (moderate-to-vigorous; $\geq 150 \mathrm{~min} / \mathrm{week}$ ) and had a high consumption of unhealthy foods and drinks, including alcohol. However, high proportion reported never having smoked. The lowest frequency of grades greater than or equal to seven was obtained for Biology and the highest for Physical Education. One third of the participants presented a high academic performance.

Regarding sociodemographic characteristics, the proportion of boys and girls was similar to that found in representative studies of Brazilian adolescents ${ }^{2}$. The predominant economic class in the present study indicates that the purchasing power of the sample appears to be greater than that of the Brazilian population ${ }^{22}$.

A nationally representative study carried out with Brazilian adolescents ${ }^{2}$ identified a prevalence $9.6 \%$ for HBP and the prevalence for BMI above the recommended was $25.5 \%$. The frequency of HBP was very similar to that found in the present study. For BMI, although different criteria were adopted, the proportion above the cut-offs was also similar. The frequency of spinal pain was lower than previously described ${ }^{20}$, this was due the fact that moderate spinal pain was used as a cut-off in the present study.

Regarding behavioral indicators, a previous study in the same city identified a higher proportion of smokers than the present study $(15.1 \%$ to $20.7 \%)$. Additionally, found a high prevalence of insufficiently physical active and unhealthy eating habits, corroborating with the results of the present study, but it is needed to consider that it were used different instruments ${ }^{8}$. The present study verifies physical activity index and $\mathrm{SEP}^{19}$ and the instrument used to investigate eating habits does not allow to know the nutrient intakes, but it makes it possible to assess dietary patterns ${ }^{15}$.

Academic achievement was assessed using grades of final results in each discipline. This measure is a criteria used on Brazilian schools for student approval for the following year or retention. The strength of using this procedure is that grades are issued by student's teachers according to subject area, reducing bias of a test applied by researchers. Furthermore, grades are the most common measure when analyzing academic achievement $^{6}$ and results of this longitudinal research will elucidate how different aspects of adolescent's health can impact this outcome.

Adolescence seems to be an essential stage in the establishing healthy 
behavior, which tend to be maintained in adult life $\mathrm{e}^{15}$, suggesting that efforts to prevent and reduce risk behaviors should be instituted during the school period, a time when young people are especially receptive to incorporating health-related behaviors into their daily lives ${ }^{8,9}$.

Some limitations must be recognized when interpreting the information in the present study. The information on physical activity and other health-related behaviors was not measured objectively. However, questionnaires has been a frequent option to verify health-related behaviors in longitudinal studies, due to acceptable validity and reliability, as well as being practical and inexpensive ${ }^{9,12}$. The sample size was calculated aiming only at estimating the frequency of HBP. In this way, it is possible that the analysis of other outcomes is limited by the sample size, requiring a posteriori calculation to identify the adequacy of the sample size. Finally, small schools were not included in the study, so the results could not be representative for the entire population. Otherwise, non-representative samples are common in longitudinal design due to logistical difficulties. It should be highlighted some positive aspects of the current study. It had a longitudinal design and evaluated potential confounding variables.

\section{CONCLUSION}

There was a high frequency of health-related outcomes, as well as a high proportion of unhealthy behaviors already in early adolescence. High academic achievement was achieved just for one third of the participants. This work will enable the verification of the tracking of health-related behaviors and biological indicators, as well as academic achievement. In addition, it will make it possible to identify the association between health outcomes and exposures prospectively, considering potential confounding variables. This information may contribute to propose intervention strategies and plan public health policies for Brazilian adolescents.

\section{COMPLIANCE WITH ETHICAL STANDARDS}

\section{Funding}

National Postdoctoral Program of CAPES (PNPD/CAPES).

\section{Ethical approval}

Ethical approval was obtained from the local Human Research Ethics Committee - State University of Londrina (number 234/10) and the protocol was written in accordance with the standards set by the Declaration of Helsinki.

\section{Conflict of interest statement}

The authors have no conflict of interests to declare. 


\section{Author Contributions}

Conception and design of the experiment: GAA, ARO. Realization of the experiments: GAA, DHCC, FPC. Data analysis: GAA, DHCC, FPC, MVGB, DASS. Contribution with reagents/research materials/analysis tools: GAA, ARO, FPC. Article Writing: GAA, DHCC, FPC, MVGB, DASS, AOBCA, CMSMF, ARO. All authors read and approved the final version of the manuscript.

\section{REFERENCES}

1. Bircher J. Towards a dynamic definition of health and disease. Med Health Care Philos 2005;8(3):335-41.

2. Bloch KV, Klein CH, Szklo M, Kuschnir MCC, Abreu GA, Barufaldi LA, et al. ERICA: prevalences of hypertension and obesity in Brazilian adolescents. Rev Saúde Pública 2016;50(suppl.1):9s.

3. Meredith MD, Welk GJ. Fitnessgram/Activitygramtest administration manual (Updated. 4. ed.). Champaign: Human Kinetics; 2013.

4. GBD 2017 Risk Factor Collaborators. Global, regional, and national comparative risk assessment of 84 behavioural, environmental and occupational, and metabolic risks or clusters of risks for 195 countries and territories, 19902017: a systematic analysis for the Global Burden of Disease Study 2017. Lancet 2018;392(10159):1923-1994.

5. Briggs AM, Jordan JE, O'Sullivan PB, Buchbinder R, Burnett AF, Osborne RH, et al. Individuals with chronic low back pain have greater difficulty in engaging in positive lifestyle behaviors than those without back pain: An assessment of health literacy. BMC Musculoskelet Disord 2011;12:161.

6. Ragnarsson S, Myleus A, Hurtig AK, Sjöberg G, Rosvall PÅ, Petersen S. Recurrent Pain and Academic Achievement in School-Aged Children: A Systematic Review. J Sch Nurs 2020;36(1):61-78.

7. Dagenais S, Caro J, Haldeman S. A systematic review of low back pain cost of illness studies in the United States and internationally. Spine J 2008;8:8-20.

8. Guedes DP, Guedes JERP, Barbosa DS, Oliveira JA, Stanganelli LCR. Fatores de risco cardiovasculares em adolescentes: indicadores biológicos e comportamentais. Arq Bras Cardiol 2006;86(6):439-50.

9. Reichert FF, Wells JC, Ekelund U, Menezes AM, Victora CG, Hallal PC. Prospective associations between physical activity level and body composition in adolescence: 1993 Pelotas (Brazil) Birth Cohort. J PhysAct Health 2015;12(6):834-9.

10. Lemes IR, Sui X, Fernandes RA, Blair SN, Turi-Lynch BC, Codogno JS, et al. Association of sedentary behavior and metabolic syndrome. Public Health 2019;167:96-102.

11. Song YM, Lee K. Eating behavior and metabolic syndrome over time. Eat Weight Disord 2020;25(3):545-52.

12. Sormunen E, Saarinen MM, Salokangas RKR, Telama R, Hutri-Kähönen N, Tammelin T. Effects of childhood and adolescence physical activity patterns on psychosis risk-a general population cohort study. NPJ Schizophr 2017;3:5.

13. Jiménez-Pavón D, Kelly J, Reilly JJ. Associations between objectively measured habitual physical activity and adiposity in children and adolescents: systematic review. Int J Pediatr Obes 2010;5(1):3-18.

14. Corrêa Neto VG, Palma A. Blood pressure and its association with physical activity and obesity in adolescents: a systematic review. Cien Saúde Colet 2014;19(3):797-818.

15. Mikkilä V, Räsänen L, Raitakari OT, Pietinen P, Viikari J. Consistent dietary patterns identified from childhood to adulthood: the cardiovascular risk in young finns study. Br J Nutr 2005;93(6):923-31. 
16. Luiz RR, Magnanini MMF. A lógica da determinação do tamanho da amostra em investigações epidemiológicas. Cad Saúde Colet 2000;8(2):9-28.

17. Silva MAM, Rivera IR, Ferraz MRMT, Pinheiro AJT, Alves SWS, Moura AA, et al. Prevalência de fatores de risco cardiovascular em crianças e adolescentes da rede de ensino da cidade de Maceió. Arq Bras Cardiol 2005;84(5):387-92.

18. American Alliance for Health, Physical Education, Recreation and Dance. Physical Best. Reston: AAHPERD; 1988.

19. Arruda GA, Cantieri FP, Coledam DHC, Ribeiro EAG, Barros MVG, Freitas CMSM, et al. Questionário Baecke de atividade física habitual: reprodutibilidade dos escores e itens em adolescentes. Arq Bras Ed Fís 2019; 2(2):15-27.

20. Arruda GA, Coledam DHC, Oliveira AR, Neri FS, Greca JPA; Cardoso JR. Proposição e reprodutibilidade de uma escala de dor na coluna cervical, torácica e lombar em jovens brasileiros. Rev Paul Pediatr 2019;37(4):450-57.

21. Collins SL, Moore RA, McQuay HJ. The visual analogue pain intensity scale: what is moderate pain in millimeters? Pain 1997;72(1-2):95-7.

22. Brazilian Market Research Association [Internet]. Brazilian Economic Classification Criteria. [cited 201010 feb]. Availablefrom: http://www.abep.org.

23. Paraná. Secretaria de Estado da Educação / Superintendência da Educação. Instrução no 011/2014 - SEED/SUED. Normatiza os procedimentos para a emissão de relatório final do sistema estadual de educação. Disponível em:<http://www. educacao.pr.gov.br/arquivos/File/instrucoes2014\%20sued\%20seed/instrucao0112014seedsued.pdf >. Acesso em: 6 abr. 2016.

24. Flynn JT, Kaelber DC, Baker-Smith CM, Blowey D, Carroll AE, Daniels SR, et al. Clinical practice guideline for screening and management of high blood pressure in children and adolescents. Pediatrics 2017;140(3):e20171904.

25. Christofaro DG, Casonatto J, Polito MD, Cardoso JR, Fernandes R, Guariglia DA, et al. Evaluation of the Omron MX3 Plus monitor for blood pressure measurement in adolescents. Eur J Pediatr 2009;168(11):1349-54.

26. Gordon CC, Chumlea WC, Roche AF. Stature, recumbent length, and weight. In: Lohman TG, Roche AF, Martorell R. Anthropometric standardization reference manual. Champaign: HumanKinetics; 1988.

27. Callaway CW, Chumlea WC, Bouchard C, Himes JH, Lohman TG, Martin AD, et al. Circunferences. In: Lohman TG, Roche AF, Martorell R. Anthropometric standardization reference manual. Champaign: Human Kinetics; 1988.

28. Harrison GG, Buskirk ER, Carter JEL, Johnsoton FE, Lohman TG, Pollock ML, et al. Skinfold thicknesses and measurement technique. In: Lohman, T.G.; Roche, A.F.; Martorell, R. Anthropometric standardization reference manual. Champaign: Human Kinetics; 1988.

29. Slaughter MH, Lohman TG, Boileau RA, Horswill CA, Stillman RJ, Van Loan $\mathrm{MD}$, et al. Skinfold equations for estimation of body fatness in children and youth. Hum Biology 1980; 60(5):709-23.

30. Burns RD, Hannon JC, Brusseau TA, Eisenman PA, Saint-Maurice PF, Welk GJ, et al. Cross-validation of aerobic capacity prediction models in adolescents. Pediatr Exerc Sci 2015;27(3):404-11.

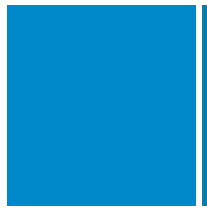

Corresponding author Gustavo Aires de Arruda

University of Pernambuco, Faculty of Nursing Nossa Senhora das Graças.

R. Dr. Otávio Coutinho - Santo Amaro.

52171-011, Recife - PE.

E-mail: arrudaga@yahoo.com.br 